\title{
Aplicación de las Tecnologías de la Información Geográfica a la gestión del patrimonio cultural
}

Silvia Fernández Cacho, Jefa del Centro de Documentación y Estudios, IAPH; Francisco Sánchez Díaz, Laboratorio de Cartografia e Imagen Digital, Centro de Documentación y Estudios, IAPH

Las Tecnologias de la Información Geográfica han

proporcionado nuevos métodos para el análisis del patrimonio cultural, en la línea de conectar los bienes patrimoniales con los restantes procesos que tienen lugar en el territorio. Estas nuevas posibilidades han renovado no sólo los procedimientos de inventario y documentación, sino también los medios de representación, difusión y sensibilización.

\section{Palabras clave}

Cartografias / Difusión / Geovisualización / Gestión /

Metodología / Patrimonio cultural / Territorio / TIG Tecnologías de la Información Geográfica / SIG Sistemas de información Geográfica

\section{INTRODUCCIÓN}

La dimensión espacial de gran parte de los bienes que integran el patrimonio histórico ha determinado que el uso de las Tecnologias de la Información Geográfica (TIG) se haya generalizado con gran rapidez desde principios de los años 1990, con algo de retraso frente a otras aplicaciones en el ámbito de conocimiento puramente geográfico y ambiental.

Además de la falta de experiencia que, con excepción de la Arqueología, tenian las principales disciplinas relacionadas con el conocimiento de dicho patrimonio en la producción y manejo de datos espacialmente referenciados, otros factores han influido en el retraso con el que las TIG se han ido integrando en la gestión del patrimonio cultural:

1. La atención preferente, poco a poco superada, que las ciencias que investigan el pasado han puesto tradicionalmente en el conocimiento de los procesos históricos, la dimensión temporal y/o estética de los fenómenos/objetos analizados frente a su dimensión espacial.

2. La a veces lenta transferencia de los conocimientos y tecnologías desarrolladas en los ámbitos de investigación a la práctica de la gestión, ya sea por falta de recursos y adecuada formación como por la escasez de investigación aplicada a la resolución de las necesidades concretas de la gestión patrimonial.

3. Las reticencias de algunas corrientes de pensamiento que han criticado el empleo de métodos y técnicas desarrollados desde y para el presente en el estudio del pasado, que simplifican la complejidad del comportamiento humano a través de fórmulas y procedimientos matemáticos.

Sin embargo, los bienes con dimensión espacial que forman parte del patrimonio cultural son actuales, contemporáneos, y se gestionan en el presente para garantizar su futuro mediante su transmisión a las generaciones venideras como parte de su legado cultural. La contemporaneidad de este legado se fundamenta no sólo en su existencia en el presente, lo que conlleva una gestión 
que lo pone en relación con otros procesos naturales y antrópicos que también se desarrollan en el mismo tiempo y espacio, sino también en su propia valoración como patrimonio cultural, valoración que se produce ya entrado el siglo XX y que no existió en la conciencia social ni en los corpus legislativos de forma generalizada hasta entonces.

Si, como entidades con reflejo espacial, los bienes del patrimonio histórico están afectados por las actuaciones territoriales actuales, su gestión desde la administración cultural ha de producirse e imbricarse con las de otras administraciones que desarrollan planes territoriales y urbanisticos u otras actividades con incidencia en la ordenación del territorio, con técnicas de producción, tratamiento, gestión y difusión de la información que la hagan compatible. La generalización del uso de las TIG ha facilitado este proceso de "homologación del lenguaje" entre Administraciones aunque, obviamente, los objetivos de gestión y los criterios para alcanzarlos a veces difieran entre unas y otras.

\section{LAS TIG Y LA CUALIFICACIÓN DE LA DOCUMENTACIÓN E INFORMACIÓN DEL PATRIMONIO HISTÓRICO}

Sin duda, la principal aportación del uso de las TIG a la gestión del patrimonio histórico, como ha ocurrido en otros ámbitos, ha sido su capacidad para procesar con facilidad grandes volúmenes de datos. Gracias a esta posibilidad resultó relativamente senciIlo disponer de una cartografía específica de grandes territorios y poder visualizar a golpe de ratón la distribución territorial de las entidades patrimoniales que tenían que ser gestionadas y su relación con otros elementos dentro del sistema territorial. De este modo las TIG se han convertido en un instrumento que acompaña la evolución conceptual y práctica de la gestión de patrimonio hacia la tutela de amplias áreas territoriales y paisajes culturales.

Este uso original y básico de las TIG puso en evidencia diversos problemas que habian pasado inadvertidos hasta ese momento y que ayudaron a depurar procedimientos y metodologias de regis-
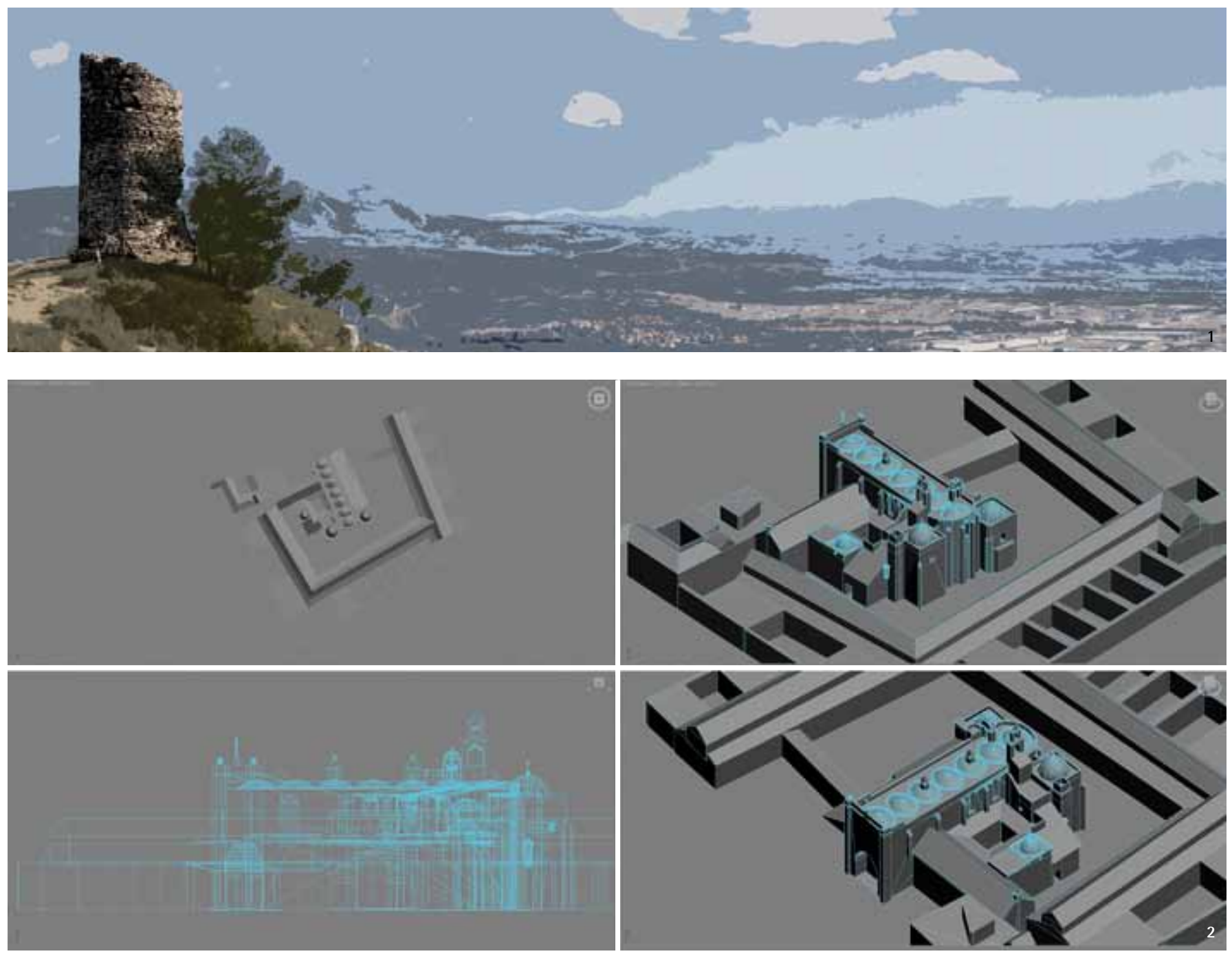

1. Interpretación digital del Torreón de Sierra Elvira (Albolote) aplicando técnicas de documentación gráfica.

Fuente: Laboratorio de Cartografía e Imagen Digital, IAPH

2. Levantamiento tridimensional del patrimonio cultural andaluz: diversas vistas de edificios del Monasterio de la Cartuja de Sevilla.

Fuente: Laboratorio de Cartografía e Imagen Digital, IAPH 
tro del patrimonio histórico, definiendo criterios para la localización y delimitación de las entidades patrimoniales, especificando los tipos de entidades representadas, normalizando vocabularios y simbologías, etc.

\section{Localización y delimitación de entidades patrimoniales}

El inicio del proceso de transferencia de la información que contenían las bases de datos alfanuméricas a plataformas SIG (Sistemas de Información Geográfica) tuvo que ser acompañado de un trabajo de depuración, corrección y normalización de la información.

La mayoría de inventarios de patrimonio arqueológico contenía información relativa a su localización espacial en coordenadas geográficas o UTM, ya que la Arqueología como disciplina había integrado de forma más temprana los conocimientos cartográficos básicos, dado que su objeto y metodología de estudio la acerca a los modelos analíticos de la Geografía humana.

Otros registros o inventarios (de patrimonio arquitectónico o etnológico, por ejemplo) incorporaban las referencias espaciales de forma más descriptiva, no sólo por la menor formación en el uso de mapas, sino también porque las entidades inventariadas se localizaban a menudo en contextos urbanos en los que la dirección postal podía ser suficiente. La extensión del uso del GPS no sólo ha facilitado la labor, sino que ha evitado errores muy usuales en la consignación de las coordenadas añadiéndole precisión, sea cual sea la escala de la cartografía base empleada. También la extensión de procedimientos automatizados de teledetección y fotointerpretación ha aportado un plus de calidad, especialmen- te cuando todas las fuentes disponibles pueden integrarse en un mismo sistema de información (MURRAY, 2002).

Las formas de representar las entidades patrimoniales tampoco han estado siempre sujetas a criterios consensuados. La más extendida fue originalmente la de un punto sobre una base cartográfica de escala pequeña cuando se trataba de representar un conjunto amplio de ellas, por ejemplo un inventario nacional/ regional. Posteriormente se ha ido procediendo a su delimitación sobre bases cartográficas más detalladas y eso ha permitido realizar análisis más complejos que han podido tener en cuenta, por ejemplo, la superficie de las entidades representadas, a la vez que se definían criterios más ajustados para realizar dichas delimitaciones (una envolvente que integrara los materiales arqueológicos detectados en superficie, un entorno mínimo en torno a un inmueble, referencias topográficas en ámbitos rurales, etc.).

Para los estudios y representaciones de detalle, las TIG ofrecen un amplio abanico de herramientas que permiten aplicar a escala objetual algunas de las funciones originalmente implementadas para amplias áreas territoriales. Ejemplos de este tipo lo constituyen los levantamientos fotogramétricos digitales de inmuebles como apoyo para su conocimiento, conservación y restauración, por ejemplo, mediante análisis estructurales, evaluación de la distribución de patologías, etc. que permiten realizar modelados virtuales para valorar desde la idoneidad de una intervención a la transmisión del conocimiento mediante productos educativos y de difusión (BALTSAVIAS; GRUEN; VAN G00L et ál., 2006)

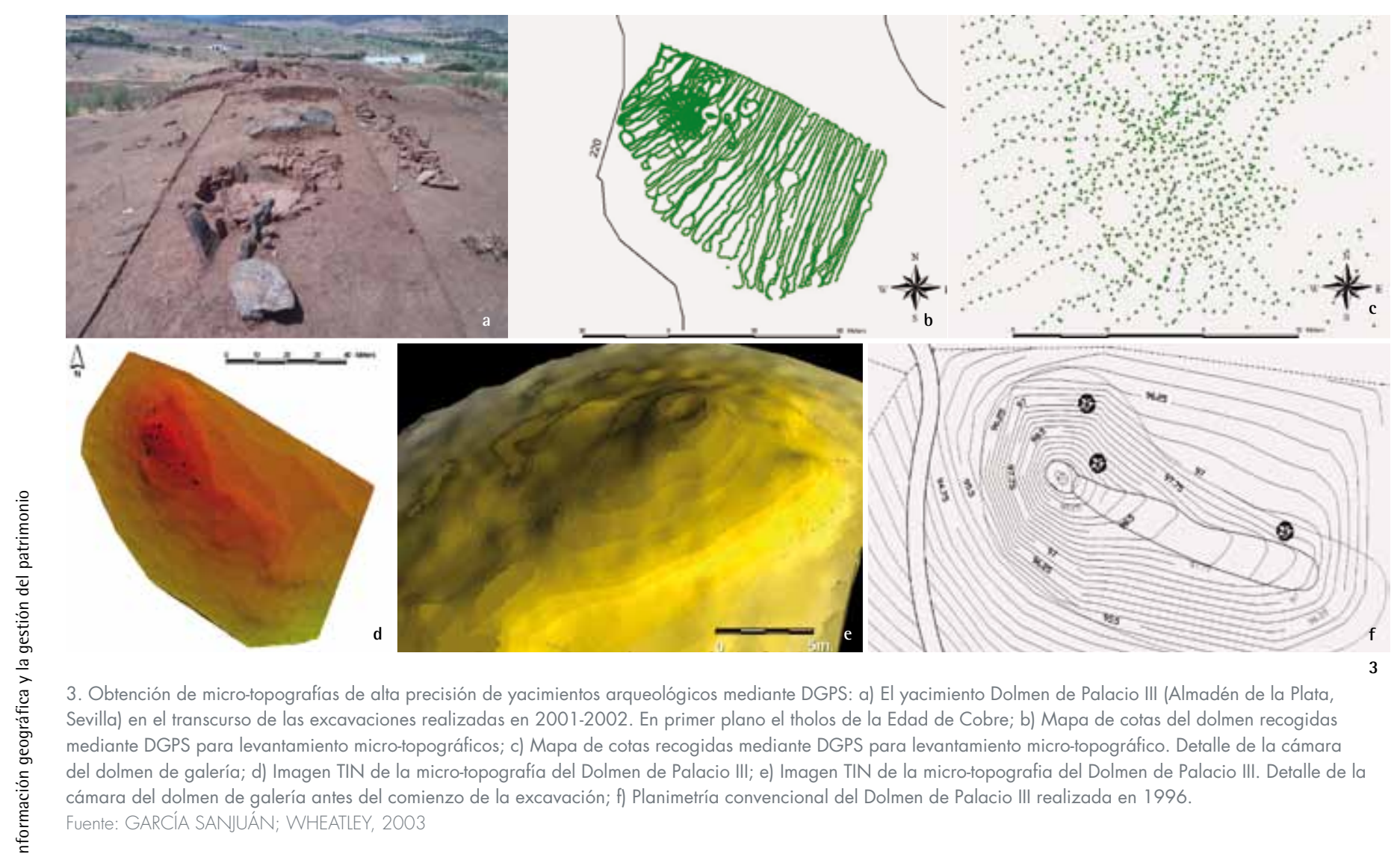


También se ha ensayado con éxito a escala objetual el levantamiento de microtopografías de terreno empleando el GPS diferencial para documentar gráficamente los sitios arqueológicos, método que podría cualificar en el futuro la gestión de los registros e inventarios de patrimonio arqueológico (GARCÍA SANJUÁN; WHEATELY, 2003).

\section{Definición conceptual de las entidades patrimoniales}

Una carencia evidenciada por el uso de las TIG ha sido la frecuente falta de definición de las entidades patrimoniales, sobre todo en la elaboración de cartografía digital de un amplio conjunto de ellas. Los registros de entidades inmuebles con valores arqueológicos, artísticos, etnológicos o arquitectónicos no han especificado normalmente las diferencias básicas entre ellas. A este respecto son dos los problemas más comúnmente evidenciados al elaborar dicha cartografía:

a) Los registros se han realizado en función del carácter de las entidades a registrar. Es decir, se han confeccionado registros de entidades arqueológicas, arquitectura vernácula, inmuebles protegidos por sus valores artísticos y arquitectónicos, etc. Una de las dificultades para gestionar todos estos inmuebles en una cartografía única ha sido la insuficiente integración de estos registros en una base de datos que proporcionara un modelo de datos común a todos ellos. Este factor también ha favorecido duplicidades ya que algunas entidades patrimoniales como, por ejemplo, la arquitectura defensiva, han formado parte de registros de patrimonio arquitectónico y arqueológico. Esta carencia se ha debido a la sectorización del conocimiento y, a menudo, a la división de la gestión en función de los diversos ámbitos disciplinares.

b) Se han registrado así mismo con la misma simbología y modelo de datos entidades de muy diversa naturaleza como por ejemplo un hallazgo arqueológico aislado, un solar en ámbito urbano con restos arqueológicos, una capilla de una iglesia o una catedral. Es importante definir el tipo de asociación que se produce entre distintas entidades explicitando tanto las jerárquicas, del tipo "entidad A" es parte de "entidad B" (o "entidad B" contiene a "entidad A"), como las asociativas, del tipo "entidad A" se relaciona con "entidad C", tal y como recomienda el Consejo de Europa (CORE, 1999). El primer tipo sería la asociación, por ejemplo, que se establece entre una capilla y el conjunto de la iglesia o un solar en ámbito urbano con la totalidad del sitio arqueológico al que pertenece. El segundo tipo de asociación puede establecerse, por ejemplo, entre un poblado prehistórico y su necrópolis. En cualquier caso, ni siquiera existe un consenso general en la definición de lo que puede considerarse un sitio arqueológico, por lo que, al menos, será necesario explicitar en cada caso que se está entendiendo por tal.

\section{Normalización de vocabularios y simbologías}

La normalización de vocabularios mediante la elaboración de tesauros y listados de descriptores no es tampoco una necesidad directamente vinculada al uso de las TIG pero, al igual que ocurria en el caso anterior, su uso se hace más inexcusable, no sólo para la realización de consultas estandarizadas sino también para la realización de cartografía analítica de mayor calidad.

El diseño de simbologías para representar cartográficamente la diversidad de entidades patrimoniales también ha sido una carencia no subsanada y que con el aumento de la producción de información espacialmente referenciada que ha provocado el uso de las TIG se ha hecho más evidente. En muchos productos de difusión de información espacial, las entidades patrimoniales se siguen representando como puntos en el territorio con información alfanumérica asociada a la que hay que acudir para conocer el periodo histórico al que pertenece o su tipología funcional.

\section{Representación de valores inmateriales}

En la actualidad, con el impulso del Convenio Europeo del Paisaje (Consejo de Europa, 2000) y la Convención para la Salvaguarda del Patrimonio Cultural Inmaterial (UNESCO, 2003), se están promoviendo la elaboración de registros de paisajes culturales y patrimonio inmaterial.

La aplicación de las TIG en la documentación de este patrimonio es desigual debido a la inmaterialidad de todos o algunos de los valores que se le atribuyen. La representación de la percepción humana y de las manifestaciones culturales inmateriales a las que se reconoce un valor patrimonial es en la actualidad un interesante desafio.

El patrimonio inmaterial suele representarse a través de la localización espacial de aquellas entidades materiales que se le asocian. Por ejemplo, si un determinado oficio tradicional se realiza en una serie de inmuebles, o una manifestación festivo-ceremonial se desarrolla en un determinado espacio público, serán los inmuebles y dicho espacio los que se localicen en la cartografía digital elaborada aunque no tengan valor patrimonial material, mientras que el modelo de datos se relacionará con la entidad patrimonial, esta vez de carácter inmaterial. No obstante, se han abierto otros caminos de mayor complejidad que se apuntarán más adelante en este mismo volumen.

La representación de los paisajes culturales tampoco está exenta de dificultades, en tanto que debe transmitir una serie de factores sólo adecuadamente perceptibles a través de los sentidos de forma directa. En este campo las TIG proporcionan modelos tridimensionales del territorio que, combinados con ortofografias de gran precisión, ofrecen vistas oblicuas que se alejan de la tradicional representación cenital, no válida para la representación del paisaje.

También se han empleado sencillos análisis de densidad de entidades patrimoniales para determinar los principales valores culturales que caracterizan el paisaje (FERNÁNDEZ CACHO; FER- 
NÁNDEZ SALINAS; HERNÁNDEZ LEÓN et ál. 2010) u objetivar sus valores históricos y simbólicos, como se ha hecho en el Catálogo de Paisajes de Lleida (TERRES, 2008).

A partir de los modelos tridimensionales del territorio es factible realizar análisis de las caracteristicas visuales de los paisajes, posiblemente los que más se han desarrollado en los últimos tiempos (calidad visual, análisis de visibilidad, fragilidad visual,...) que pueden se útiles no sólo en la delimitación de los paisajes culturales, sino también en la evaluación de los posibles impactos que puedan afectarles o en la elección de miradores y corredores paisajísticos.

\section{Definiendo criterios y priorizando acciones en el territorio}

En el apartado anterior se ha realizado un rápido recorrido por las aplicaciones más usuales de las TIG para la gestión del patrimonio histórico. Dichas aplicaciones han servido fundamentalmente para cualificar su documentación y el almacenamiento y gestión de la información patrimonial, la precisión en las localizaciones y la apertura de nuevos modos de visualizarla y difundirla.

A partir de este punto el verdadero reto consiste en aprovechar las prestaciones que ofrecen para sustentar, a partir del adecuado procesamiento de la información que almacenan, la evolución y ampliación tanto de los objetivos de la propia gestión patrimonial como del objeto de la misma.

La gestión del patrimonio histórico ha evolucionado desde los inicios del siglo XX, cuando el foco de atención se situaba en los objetos muebles, sujetos a menudo al tráfico ilícito de obras de arte, a los territorios y paisajes culturales que son gestionados a principios del siglo XXI, además del patrimonio inmaterial. El motivo de fondo de esta atención particular se basa fundamentalmente en la percepción del riesgo en el que se encuentran por la depredación contemporánea del territorio y la pérdida de la diversidad cultural frente al proceso globalizador.

La pregunta a la que se enfrenta la gestión del patrimonio histórico en la actualidad y que el empleo de las TIG puede ayudar a responder es: ¿en qué áreas del territorio hay que priorizar las actuaciones de investigación, conservación o difusión del patrimonio histórico?

En este punto se encuentran quizá los aspectos más novedosos y las aplicaciones más avanzadas de las TIG en la gestión del patrimonio histórico. Cabe citar en este contexto de forma especial las cartas de riesgo territorial y urbano y los modelos predictivos².

Las cartas de riesgo territorial se han abordado desde dos ópticas complementarias: las que ponen el acento en factores territoriales que pueden incidir en el estado de conservación de las entidades patrimoniales (que también son evaluadas), como en el caso de Italia ${ }^{3}$, y las que valoran el propio estado de conser- vación de dichas entidades para priorizar las necesarias intervenciones que puedan realizarse sobre ellas, como en Irlanda o Inglaterra a través de los proyectos AFAR, Archaeological Features at Risk (O'SULLIVAN; O'CONNOR; KENNEDY, 2000), y MARS, Monuments at Risk Survey (BELL; KING, 1996; DARVILL; FULTON, 1998), respectivamente. En cualquiera de los dos casos la recopilación, tratamiento, ponderación y cartografiado de variables de análisis ha sido compleja y, por tanto, su aplicación no ha sido muy extendida.

Por otra parte, se han desarrollado cartas de riesgo en ámbitos urbanos en las que, tras un registro georreferenciado de las entidades patrimoniales conocidas en una determinada ciudad, su secuencia estratigráfica, las características de las construcciones existentes y las noticias históricas que documentan determinadas remociones de terreno, se hace una proyección de las caracteristicas y estado de conservación del patrimonio histórico, fundamentalmente arqueológico, no conocido pero previsiblemente existente. Con la nueva cartografía elaborada, se redactan e integran normas y recomendaciones en los documentos de planificación urbana asociadas a los niveles de cautela con carácter previo al desarrollo de cualquier actividad urbanistica que requiera remociones del subsuelo de la ciudad. Las cartas de riesgo urbanas han sido propiciadas por el avance normativo y práctico de la Arqueologia urbana ${ }^{4}$.

Los modelos predictivos son, por otra parte, el resultado de una de las aplicaciones más prácticas y avanzadas en la gestión del patrimonio histórico. Estos modelos se han aplicado en Arqueología para elaborar áreas de potencial arqueológico a diversas escalas territoriales. Sin embargo, para la gestión del patrimonio arqueológico, resulta más práctica su aplicación en superficies territoriales amplias (escala pequeña) como paso intermedio entre el conocimiento recopilado a través de registros generales y el conocimiento total esperado, al que es difícil llegar tanto por el coste de la realización de prospecciones arqueológicas intensivas en territorios amplios como por la invisibilidad de parte del registro arqueológico por las características de algunos sitios, así como por el uso del suelo actual que puede dificultar su visibilidad mediante el reconocimiento superficial.

\section{DIFUSIÓN Y SENSIBILIZACIÓN SOBRE EL PATRIMONIO}

Las TIG no sólo han permitido una innovación en los procesos de inventario, documentación y análisis del patrimonio cultural, sino que están demostrando una gran capacidad para transmitir esta información a la ciudadanía, contribuyendo de esta forma a la sensibilización pública sobre el valor del patrimonio y su necesidad de preservación. A este nivel, la representación cartográfica tiene una capacidad de comunicación muy superior a los inventarios formalizados en bases de datos, ya que su componente visual se integra mejor con las formas de la cultura contemporánea, en la que cada vez predominan más los contenidos gráficos. 


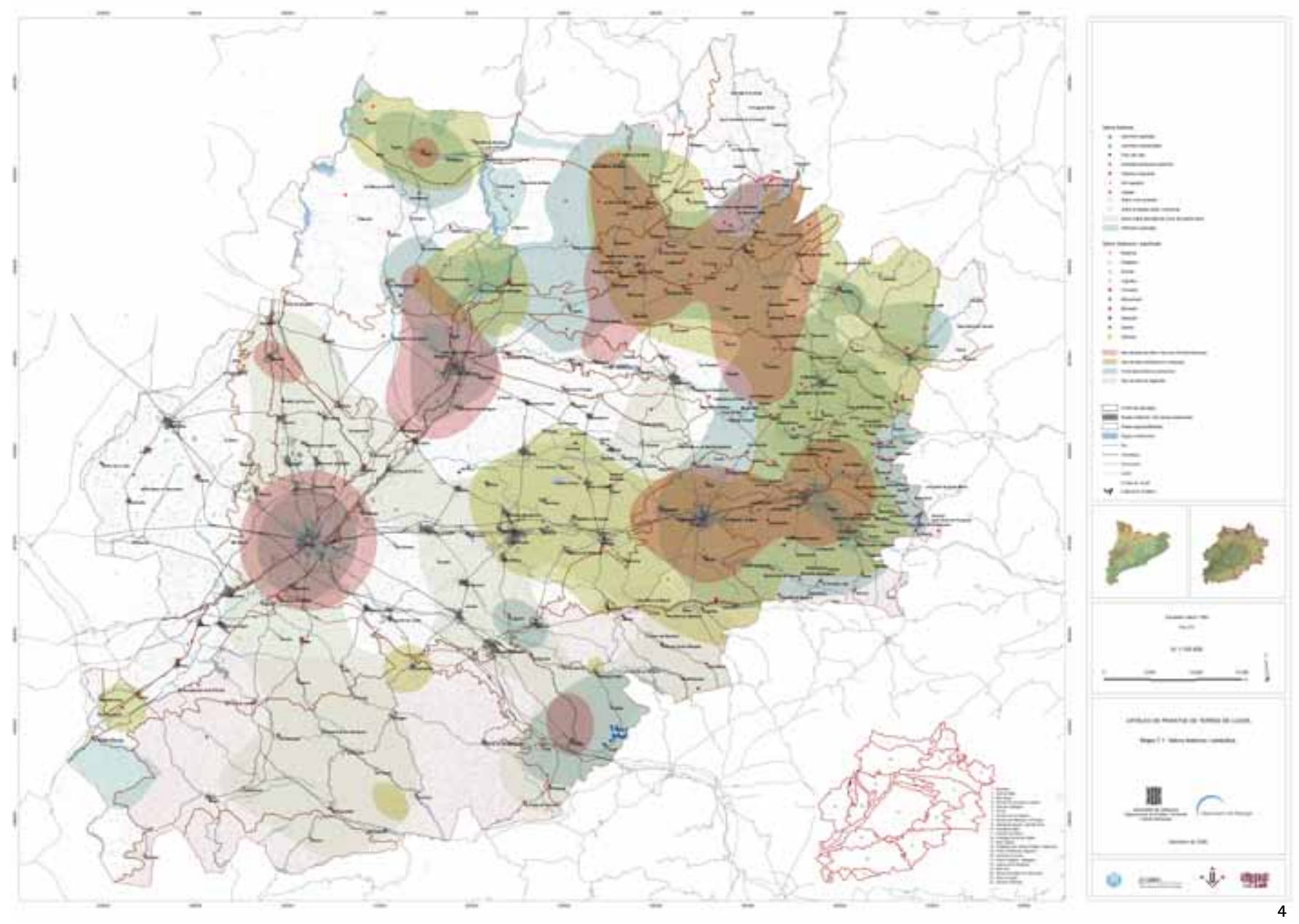

4. Valors històrics i simbòlics de Lleida. Fuente: TERRES, 2008

La cartografia ha sido tradicionalmente un medio muy eficaz para la transmisión sintética de grandes volúmenes de datos. La semiología gráfica que se ha ido desarrollando a lo largo de siglos para el diseño de mapas ha alcanzado una gran capacidad de transferencia de información, pudiendo combinar variadas formas de describir los fenómenos que se dan sobre la superficie terrestre (AGUILERA ARILLA et ál., 2003). En este terreno las TIG han abierto nuevos estilos, formas y estéticas para comunicar la información geográfica, además de novedosos canales y soportes ${ }^{5}$.

Las TIG también han supuesto un cambio en los procedimientos mediante los cuales se difunden entre la ciudadanía y los investigadores los valores de nuestro patrimonio histórico. La consulta de un inventario arqueológico mediante su representación sobre cartografia digital, por ejemplo, permite poner esas localizaciones arqueológicas en relación con la información territorial que aportan nuevas bases cartográficas como las ortofotografías o los modelos de elevaciones. A otro nivel, la representación de un paisaje cultural mediante un vuelo virtual sobre una vista tridimensional ofrece una visión mucho más rica que la habitual perspectiva cenital del mapa.

Estas nuevas formas de la imagen cartográfica requieren además un menor nivel de conocimientos técnicos para entenderlas e interpretarlas, con lo cual tienen una capacidad para llegar a la ciudadanía general que no tenían los soportes cartográficos tradicionales. Basta con comparar una visión del relieve en perspectiva con un mapa de curvas de nivel para constatar que los soportes digitales que ofrecen las TIG facilitan la comunicación entre los gestores del patrimonio y los destinatarios no técnicos.

Además de una nueva semiologia, las TIG aportan también nuevos canales y soportes para difundir la información sobre el patrimonio. A este nivel, los mapas en Internet están resultando un medio muy eficaz para comunicar la localización y características de los principales bienes integrantes del patrimonio cultural. Independientemente de la valoración sobre si publicar la situación del patrimonio con precisión geográfica contribuye a preservarlo o a facilitar su expolio, como canal de comunicación la web se ha convertido en el medio privilegiado para contactar con un público masivo, sobre todo cuando el patrimonio tiene además de su valor cultural un interés turístico.

A este nivel hay múltiples ejemplos de visores cartográficos en Internet con información patrimonial. La propia UNESCO ha acordado con Google que la información sobre los bienes declarados como Patrimonio Mundial aparezca recogida en Google Earth. A nivel europeo es sin duda el English Heritage el orga- 
nismo que más ampliamente utiliza los mapas en Internet para difundir su documentación patrimonial. Y en España se puede citar el Localizador Cartográfico del Patrimonio Cultural Andaluz, publicado por el Instituto Andaluz del Patrimonio Histórico, como uno de los productos de difusión en web más avanzados ${ }^{6}$.

Las Infraestructuras de Datos Espaciales están suponiendo un nuevo paso en la tendencia hacia la utilización de Internet como el medio privilegiado para difundir la información geográfica sobre el patrimonio histórico. Frente a las páginas web con mapas, las IDE ofrecen servicios estandarizados e interoperables que permiten consultar la localización de los bienes patrimoniales desde una gran variedad de entornos informáticos, ya sean terminales móviles, navegadores web o sistemas de información geográfica. Entre los contenidos obligados por la normativa europea y española para las IDE se encuentran los lugares protegidos -sin distinción entre su carácter natural o cultural- y de hecho la IDE de España ha constituido un grupo de trabajo para armonizar la publicación de las afecciones territoriales derivadas de la legislación sobre patrimonio histórico.

La evolución de Internet hacia lo que ha venido en llamarse "web 2.0" está haciendo que aparezca una nueva forma de gestionar la información patrimonial (GARTNER, 2009). Más allá de entender la web como un medio de comunicación, la "neogeografía" está utilizando Internet como una plataforma para la realización de mapas colaborativos en los que una multitud de usuarios -no necesariamente técnicos- comparten sus datos espaciales. La aplicación de estos nuevos procedimientos de captura y publicación de información geográfica al campo de la documentación patrimonial permitirá que la ciudadanía sea no sólo destinataria de las acciones de difusión, sino agente de las mismas. Estos procedimientos colaborativos están demostrando ser más efectivos para la sensibilización pública sobre la preservación de nuestro patrimonio, ya que hace a la ciudadanía partícipe de la misma.

\section{Notas}

${ }^{1}$ Un resumen de este proceso en España puede consultarse en Fernández Cacho y Villalón Torres (2009: 29-39).

2 Una visión ampliada de este tipo de aplicaciones a nivel nacional e internacional puede consultarse en Fernández Cacho (2009: 191 y ss).

${ }^{3}$ El proyecto llevado a cabo por el Istituto Centrale per il Restauro (ICR) en Italia (PaCAR) surgió como medida preventiva ante el riesgo sísmico del territorio italiano que ha dañado a menudo su patrimonio histórico (CARTA, 1996; W. AA., 1992). ${ }^{4}$ Un estudio general de la Arqueología urbana en España en Rodríguez Temiño (2003).

${ }^{5}$ Ejemplos de novedosos diseños cartográficos pueden consultarse en http://www. visualcomplexity.com

${ }^{6} \mathrm{http}$ ://www.juntadeandalucia.es/cultura/iaph/nav/navegacion.

jsp?seccion=PRODUCTOSEtentrada=/portal/Productos/localizador_cartografico/

\section{Bibliografía}

AGUILERA ARILLA, M. J.; AZCÁRATE LUXÁN, M. V.; GONZÁLEZ YANCI, M. P. et ál. (2003) Fuentes, tratamiento y representación de la información geográfica. Madrid: UNED, 2003

BALTSAVIAS, E.; GRUEN, A.; VAN G00L, L. et ál. (ed.) (2006) Recording, modeling and visualization of cultural Heritage. Proceedings of the International Workshop (Centro Stefano Franscini, Monte Verita, Ascona, Switzerland, May 2227, 2005). London: Taylor \& Francis, 2006

BELL, M.; KING, N. (1996) The MARS Project - an interface with England's past. En KAMERMANS, H.; FENNEMA, K. (ed.) Interfacing the Past. Computer Applications and Quantitative Methods in Archaeology (1995). Leiden: University of Leiden, 1996, pp. 87-91

CARTA del Rischio del Patrimonio Culturale. Roma. Istituto Centrale per il Restauro, 1996 (3 volúmenes)

CORE data standard for archaeological sites and monuments. Strasburgo: Council of Europe Publishing, 1999

DARWILL, T.; FULTON, A. K. (1998) Mars. The Monuments at Risk Survey in England, 1995: Main Report. Bournemouth and London: Bournemouth University and English Heritage, 1998

DíAZ IGLESIAS, J. M. (2010) El Servicio de Cartografia Digital del Instituto Andaluz del Patrimonio Histórico. PH Boletín del IAPH, n.o 73, 2010, pp. 32-41 FERNÁNDEZ CACHO, S. (2009) Bases conceptuales y metodológicas de los modelos predictivos en Arqueología. En FERNÁNDEZ CACHO, S.; RODRIGO CÁMARA, J. M. (coord.) MAPA. Modelo Andaluz de Predicción Arqueológica [en línea] e-cuadernos, n. ${ }^{\circ}$. Instituto Andaluz del Patrimonio Histórico, Consejería de Cultura, 2009, pp. 8-32 <http://www.juntadeandalucia.es/cultura/iaph/nav/ modeloandaluzdeprediccionarqueologica> [consulta: 01-11-2010] FERNÁNDEZ CACHO, S.; FERNÁNDEZ SALINAS, V.; HERNÁNDEZ LEÓN, E. et ál. (2010) Paisaje y Patrimonio Cultural en Andalucía. Tiempo, Usos e Imágenes. Colección PH Cuadernos, n. 27, 2v. Sevilla: Instituto Andaluz del Patrimonio Histórico, Consejeria de Cultura, 2010

FERNÁNDEZ CACHO, S.; VILLALÓN TORRES, D. (2009) From the Archaeological Heritage Inventories to the Historical Landscapes of Spain. En Listing archaeological sites, protecting the historical landscape. Târgoviste (Romania) 6-7 March. Brussels: Europae Archaeologiae Consilium, 2009, pp. 29-39 GARCÍA SANJUÁN, L.; WHEATLEY, D. (2003) Obtención de micro-topografias de alta precisión de yacimientos arqueológicos mediante DGPS. Mapping. Revista de Cartografía, Sistemas de Información Geográfica, Teledetección y Medio Ambiente, n. ${ }^{\circ}$ 89, 2003, pp. 94-98

GARTNER, G. (2009) Applying Web Mapping 2.0 to Cartographic Heritage. e-Perimetron [en línea], v. 4, n. ${ }^{4}$, 2009, pp. 234-239<http://www.e-perimetron. org/Nol_4_4/Gartner.pdf> [consulta: 01-11-2010]

GIBSON, T. H. (2005) Off the shelf: Modeling and Management of historical resources. En VAN LEUSEN, M.; KAMERMANS, H. (ed.) Predictive Modelling for Archaeological Heritage Management: A research agenda. Nederlandse Archeologische Rapporten 29. Amersfoort: Rijksdienst voor het Oudheidkundig Bodemonderzoek, 2005, pp. 205-223

MURRAY, D. (2002) The integration of Data Sources. En GARCIA SANJUÁN, L; WHEATLY, D. W. (ed.) Mapping the future of the past. Managing de Spatial Dimension of the European Archaeological Resource. Sevilla: Universidad de Sevilla, Secretariado de Publicaciones, 2002, pp. 139-150

O'SULLIVAN, M.; O'CONNOR, D.; KENNEDY, L. (2000) Archaeological Features at Risk Project. Dublin: The Heritage Council, 2000

RODRÍGUEZ TEMIÑO, I. (2003) Arqueología Urbana en España. Barcelona: Ariel Patrimonio, 2003

TERRES de Lleida : catàleg de paisatge [en línea]. Observatori del Paisatge de Catalunya, Generalitat de Cataluña. Departamento de Politica Territorial y Obras Públicas, $2008<$ http://www.catpaisatge.net/esp/cataleg_presentats_ter_lleida. php> [consulta: 01/11/2010]

W. AA. (1992) La Carta de Riesgo. Una experiencia italiana para la valoración global de los factores de degradación del Patrimonio Monumental. Serie Cuadernos II. Sevilla: Instituto Andaluz del Patrimonio Histórico, Consejería de Cultura, 1992 